\title{
Public Organisations and Public Management in Greece: The Implementation of Private Management Tools in the Public Sector
}

\author{
Panagiota Xanthopoulou , Vassilis Kefis
}

\begin{abstract}
The public sector in Greece faces an increasingly urgent challenge today. There is a strong need to find the ways and set the measures to reform it in depth with long-lasting outcomes. These reforms depend on a new structured public administration to carry them through. The present paper analyses the basic concepts and the most important theoretical approaches to the cognitive subject of public administration and public policy, while thoroughly examining the attitudes that make up the public policy cycle in the light of different theoretical approaches. In addition, the most important reformist trends are presented as vital proposals in the traditional form of public administration and policy.
\end{abstract}

Keywords: New Public Management, Public Administration, Public Sector, Reformation

\begin{abstract}
Introduction
By the time that the governments decided to produce pure public goods, and sometimes private ones, is met by public organisations that they are subject to control. Economic activity in Greece is characterized by the operation of public enterprises, organizations and services, units of strategic importance for economic and social development. A prerequisite for their proper operation is the creation of a modern and efficient system of administration and management, within Western European countries, adapted to Greek culture and practice and supported by individuals (executives) capable and, above all, scientifically trained and effective ones.
\end{abstract}

The business activities of Greek government cover a wide range of private goods, resulting in similarities between public and private enterprises. The different purposes and objectives and ownership are the elements that differentiate public from private economic units. More specifically, the main purpose of private enterprises is to maximize profit, while publicizing the maximization of the social welfare function. So, we can see a first discrimination between the public and private goods. The public goods are characterized as nonexclusive regarding their use and non-competitive unlike the private ones which are competitive and for an exclusive use. For the personal use of a pen refers to a private good because the person who uses it, he deprives its use from another person. On the other hand the national defense of a country can be "used" at the same time from every citizen of a country. It is very interesting the intermediate situation which refers to those goods which are in the middle of the above discrimination. A typical example could be the public roads of a country. They are available to everyone so they could be considered as a public good, however if everyone uses them then no one could be benefited due to the traffic which will be caused [5]. Furthermore, the borders between public and private sector are becoming even more discrete due to the increasing involvement of the private and non-governmental organizations in subjects of public administration and public policy. A characteristic example is the private and public sector partnerships, where the public sector for example, outsources to the private one the provision of specific services [7]. In addition, the definition of the public sector differs from one country to another. Within the West democracies, there are also differences related to the methods of intervention and policy areas. The discussion on the differrent types of capitalism underlines that in every social transformation the intervention of the state is different due to the differences in history, the culture and the social capital of each country. $[3,14]$

\section{CORE VALUES OF THE ADMINISTRATIVE REFORM}

The contemporary reform effort, known as "New Public Management" is based on classical economic theories and more specifically on the theory of individualism. There follows a liberal logic of liberalizing the markets from state commitments and public sector reform with increasing private sector involvement, as well as practices inspired by private companies [20]. The basic

This article is published under the terms of the Creative Commons Attribution License 4.0 Author(s) retain the copyright of this article. Publication rights with Alkhaer Publications. Published at: http://www.ijsciences.com/pub/issue/2019-03/

DOI: 10.18483/ijSci.1965; Online ISSN: 2305-3925; Print ISSN: 2410-4477 
values that govern this regulatory trend are: "economy", "efficiency" and "effectiveness".

Economy: One of the main reasons for the reform is the need for resource saving and therefore economics is one of the core values that govern every reform. The development of the welfare state in western societies and the increase in its spending has led to strategies to reduce spending, particularly in the 1990s, where economic pressures intensified. Economics, therefore, exclusively concerns the reduction of public sector expenditure [12].

- Efficiency: Efficiency is a private sector-inspired value that concerns both public organizations as units and the public sector as a whole. One of the more classic definitions is that of Etzioni (1964) [1], according to which the efficiency of an organization depends first on the degree to which it achieves its goals and secondly on the resources it uses to produce the desired result. Thus, according to Etzioni (1964), profitability also includes the concept of efficiency (whether the organization achieves its objectives), but also the concept of productivity (what resources an organization has to achieve its objectives). McKean (1958) observes that pursuing profitability is tantamount to both increasing positive outcomes and achieving the goals, reducing negative impacts and lowering costs [23].

- Effectiveness: Effectiveness is the third core value that is found in the reforms that are inspired by the New Public Management. As can be seen from the previous definition, it is a component of efficiency and focuses on whether a policy or program achieves its objectives [12].

The values of the New Public Management soon widened, as it was understood that a reform to be successful should include more economic parameters. The term "governance" is used in order to show the complexity of the reform processes and in order to give emphasis to the role of the people. Two core values that pointed are the "legitimacy" and the "accountability". Furthermore, emphasis was given in the competence of making logical decisions and in the satisfactory implementation of them, as so as in the "respect of the law and of human rights" [20]. The liberal values of New Public Management can be summarized as follows:

- Legitimacy: which refers to the democratic process and the people's right to agree or disagree with the actions of the public state. Emphasis is given in the existence of mechanisms that give the possibility of questioning the government [20]

Accountability: directly connected with Legitimacy. It refers to the responsibility of the politicians and public servants concerning their actions and the use of public resources. It is a symbol of "good governance" and it is a vital condition to ensure transparency [16]

In recent decades, we have seen four main reformist trends: (a) the market, involving the partial or total privatization of selected public services and public enterprises, the adoption of private sector practices in the public sector, the creation of internal markets and the choice of (b) strengthening the involvement of public officials in decision-making and empowerment of citizens; (c) regulatory reform based on deregulation (d) flexible governance that proposes to create more flexible structures that can respond to modern challenges more efficiently and quickly.

A key practice of administrative reform is decentralization, which can take various forms such as political and / or administrative decentralization, territorial, competitive, internal or external decentralization and horizontal or vertical decentralization. Other practices are the introduction of new forms of control, such as the creation of independent authorities, evaluations, audits, use of indicators and measurement in the public sector. Reforms are also observed in the management of human resources with forms of flexibility, performancebased wages, and decentralization. Finally, a modern practice is e-Government, which uses information technology to improve administration as well as to empower citizens' participation in the democratic process

Public enterprises and organizations are the backbone of the economic system, since they produce goods and services that are indispensable for the smooth operation of the other branches of the economy. Depending on the degree of participation and intervention (ownership) of the government, they are divided into:

- Public Enterprises fully dependent on the public (government). Their main characteristics are dependence on government bodies and relative financial independence.

- Public enterprises operating as public limited companies with $51 \%$ government ownership or semiautonomous enterprises. They operate under private economic criteria, are financially accountable and are 
controlled by public holding companies. Their characteristic feature is flexibility and flexibility in making decisions. Decisions on current operating issues (production, commissions, recruitment, and staff development) are taken by the company's management, while strategic planning, planning, pricing policy decisions are taken by the Central Administration.

- Public enterprises operating with full administrative autonomy or fully autonomous enterprises. They are fully financially independent, operate under private economic criteria and governed by private law. Their main advantage is the flexibility and the realization of their decisions and their disadvantage lies in the fact that the public interest for which they were created is not safeguarded.

Current socio-economic conditions, with special requirements and labor relations that increasingly employ and mobilize the human resources of public enterprises, lead to the need for clear decoding and exploration of specific concepts to avoid conflicts and misunderstandings within the units' internal environment. The in-depth, scientific (without the rejection of the technocratic) analysis of terms that support a rational and flexible system of critical situations and constitute a pillar of an anthropocentric view of things is a necessity and reinforces the profile of a man who believes that empowerment, lifelong learning and self-managing, give a qualitative dimension to the whole process. Keywords that give a different dimension to the performance of public management executives are good governance, efficiency and collaboration.

\section{II.A NEW BUSINESS MODEL FOR THE PUBLIC SECTOR}

The "public-centralized" nature of Greek productive identity, faced with a social legitimacy crisis, tends to turn into a "privatized" one through privatization, mergers, acquisitions, synergies and strategic alliances. This section focuses on the search for a new business model for economic units that will result from the political leadership announcements on "mergers and abolition of public sector bodies", which will incorporate a social vision with the ultimate goal of social acceptance and enlargement of their mission, a groundbreaking leadership with modern perceptions that respond to increased social needs and expectations and a way of making decisions based on sustainable and pragmatic solutions to more integrated values of responsibility and public accountability.
Recent mergers of public agencies have been announced to reduce costs and operating costs. Organizations reporting, under-operating, were lossmaking and came from the full range of government action (health, tourism, construction, TV, research centers, institutes, processing). This strategic move to restructure the government is imperative to create a new "strategic architecture" in the country's public sector, characterized by a change of reframing, reinforcement with new skills and competencies (renewal), incorporation of new concepts and revitalization [26].

These moves, shielded from feasibility and opportunism, must be based on a scientific basis, with the pillar of effective management that will lead to their sustainability and will serve as a springboard for sustainable development. The next step is to develop a complete organizational chart to capture the needs of the new organizations. In the second stage, within the new entrant, a new policy needs to be developed by removing or merging similar departments or departments that have been overcome by developments and creating new, innovative ones that prevent developments.

The systematic benchmarking of strategies, functions, procedures and practices with corresponding government units abroad that use best practices and their adaptation to Greek data is deemed necessary [24]. This process can have remarkable results if it is based on the following basic principles:

1. Recognition of this action

2. Selection of the relevant public organization abroad

3. Collection and analysis of data

4. Setting performance targets

5. Implement the plan and control the results

The National Strategic Reference Framework (ESPA in Greek) looks forward to innovation, research, technology, entrepreneurship, investment and sustainable development to improve the country's competitiveness, improve quality in education and strengthen the administrative capacity of public administrations services.

The environment in which these new units are expected to operate is dynamic and continually changing. The organizational changes that will result from reorganization programs and information technology require constant assessment, adaptability and flexibility that lead to constant change-conversions. In spite of the reactions, due to the culture that has been established 
for decades on the introduction of innovations, there is space for adoption. The new technology through Enterprise Application Integration (EAI), Service Oriented Architecture (SOA), Performance Management software, Business Process Management (BPM) systems and Six Sigma methodology to redesign a process is able to lead networking organization, efficiency of processes rather than resource efficiency, and efficiency of organization rather than operational efficiency. The introduction of Balanced Scorecard, Cosourcing, In-sourcing in the public sector helps simplify and better manage business processes, improve citizens' satisfaction, increase worker productivity without labor intensification, and reduce operating costs by using a realistic cash-flow.

The catalysts that will give the necessary impetus to the newly created public services and will bind them to the restarting cycle of the Greek economy and society are:

1. Changing management methods

2. The adoption of best practices

3. The bottom-up communication

4. The new technology

5. The modernization of the institutional framework and the public reporting.

The common point among all the management styles mentioned in the international literature is the fact that the effective manager whoever follows the system will make mistakes. And in many cases even more mistakes lead to even better solutions for the good of the organization and society.

\section{THE PRIVATE MANAGEMENT TECHNIQUES IN THE PUBLIC SECTOR \\ A. The adoption of NPM}

The new revised administrative perspective in public administration departs from the costly bureaucratic model that emphasized the pyramid organization, the linear cause-effect relationship, the restrictive interpretation of the rules, the inputs and inputs, without concern for producing results / outputs and outcomes, and shifts the interest in network management, accountability, results produced and consultation with society and institutions (NGOs, private law organizations, citizens' associations, etc.) [3]. It is indicative that $6.8 \%$ of GDP in our country was devoted to bureaucracy when the EU average was $3.5 \%[6]$.

Since 1990, the adoption of the New Public Management standards has already been established. The first trend, mainly from the United States and the
$\mathrm{UK}$, refers to the incorporation of a package of measures that will keep public administration the main part of public services, privatize what is best done by the private sector or agencies, in the context of a transition, from a single administration system to a fragmented one, with emphasis on specialization and the allocation of responsibilities. The shift from a public administration based on the application of the principle of bureaucracy to respect rules, legality and process towards a professional public administration that emphasizes flexibility, the good use of public resources, quality and provision [10] is the focus of the reform through modern management tools such as targeting, quality, monitoring of performance through indicators, internal control, redesign of processes and digital administration.

Such modern public management tools that are being promoted are

\section{B. Performance Management}

The term "Performance Management" is used to describe all those techniques that are used to design, measure, evaluate, and implement administrative functions that deliver the organization's highest efficiency. Performance management on the merits consists in highlighting the key performance criteria of an organization, measuring it during its production, and ultimately linking the budget / standard criteria to results10. In this process, particular attention should be paid to choosing the right way to measure efficiency. Efficiency measurement is a very important stage in performance management, where we need to pinpoint where we are in relation to what we want to go by linking performance management to performance improvement and growth. This process is of particular importance, as Osborne and Gaebler report: "If it does not measure results, you cannot separate success from failure." [7] The record of the level of efficiency consists of an extremely difficult but critical process. The difficulty lies in the fact that both quantitative and qualitative elements that will determine the level of profitability have to be taken into account. It is a fact that performance management has a direct correlation with management by objectives (Management By Objectives).

\section{Management through objectives and results}

Establishing concrete, measurable, agreed, realistic and achievable targets over a specific timeframe is expected to boost the efficiency of public services and positively influence the assessment of the resources needed to enhance the efficiency of public services. Monitoring based on results-based management is conducted through quantified indicators tailored to objectives and 
takes on the concept of organizational performance control as well as individual control, with accountability and accountability responsibility of the civil servant. In addition, targeting is not limited to the individual level, but is also combined with the division of objectives in order to enhance team performance and co-operation among employees.

\section{Business Process Reengineering in the Public Sector}

According to Hammer \& Champy (2005) the Redesign of an organization's business processes refers to fundamental revision and radical redesign of business processes and organizational structures to achieve dramatic improvements in critical performance measures such as: cost, quality, service and speed [19]. Some ways of redesigning procedures in the public sector are: the abolition of a Regulatory Arrangement, the abolition of the imposition of a liability to citizens resulting from a regulatory provision (for example, using accountable declarations or ex officio search for supporting documents), the reduction (e.g. exception to large groups of users), simplification of terminology to make citizens familiar with the text of a regulation, abolition of obsolete forms, checks, simplification of forms ( simpler, more attractive, etc.), elasticity in the criteria (e.g. abolition of controls on consistent traders, etc.), reducing the frequency of searching for information by citizens, searching for data on its own and not by the taxpayers themselves, the search of data electronically by the citizens, the enhancement of one stop shops, the abolition of the obligation to submit originals or certified copies of documents ( $\mathrm{N}$. 4250/2014), et al. [2].

The right use of New Technologies and Digital Governance

"e-Government" is defined as the method by which Governments use the most pioneering Information and Communication Technologies (ICT), in particular Web-based web applications to provide citizens and businesses with more convenient access to government information and services, improve service quality and provide greater opportunities for participation in democratic processes and institutions» [11]. Better use of e-Government is aimed at facilitating the interaction of public services, interoperability between software systems, exchange of information and automation of public administration activities, better service of citizens, etc. [8].

\section{E. Modern training methods for executives in the face of competitiveness}

A first category of interventions also aims to save resources through human resources management reform. Here, the arrangements concern the rationalization of human resources management, the better placement of staff with regard to the use of modern organizational charts, the evaluation of staff and the improvement of performance management of public services through them.

The methods of training and development of the staff vary. They are divided into two major categories, depending on whether they are applied during on-thejob training methods or off-the-job. Beyond conventional methods there is a tendency to supplement them. In this article we refer to the most popular parallel and necessary - modern training methods that take place within the working environment of a modern economic unit.

\section{i. Staff training during working hours}

Work-based training is used at all levels of the administrative pyramid. The instructor-trainer position is assigned to one or more experienced supervisors. The advantages of this method are the lower cost, the use of special rooms and specialized training material, the learning is directly applicable, the questions are solved on the spot, it allows the direct assessment of the trainee's course and the use of new knowledge, while the trainee produces work and increases the efficiency of work. The main disadvantage of this method is the fact that the trainer does not succeed in applying the correct way of learning, while the time is spent both by the trainee and by the trainer as the time of training does not perform the daily tasks that are postponed for later. The most important forms of this kind of training are:

\section{ii. Job Rotation}

The trainee moves into a series of positions in a different subject to gain new experiences and the ability to address a variety of problems, acquiring a global view of the overall operation of the business. It is one of the most applied methods that provide multiple benefits for the executive and business itself. The length of time spent in one of the positions is determined by the ability and speed of learning that distinguish the learner, but usually for a period of 3-6 months. With this method, the executive is not limited to a career of a specialist, for example, a sales or financial manager, but acquires knowledge to help him take over general administrative positions.

By acquiring new experiences, the daily routine is reduced and the interest and the availability of the strain are increased. Also, this way of training helps to 
develop interpersonal relationships between the employees of the company, which contributes to crosssectional cooperation. If the training is done in another country then the trainee knows not only the culture of his partners but also that of the clients of the company, which adds a competitive advantage. Through alternating positions the trainee finds his strengths and weaknesses something that will help him better plan his career.

However, this method also presents some drawbacks, such as the risk that the educated member is aware that staying in this position for a short period of time may be indifferent and perform their duties loosely. Also, if rotation is not well designed to give the learner the time to acquire in-depth knowledge, it can lead to half-life, which is sometimes worse than ignorance. Lastly, valuable time is wasted until the member meets the new section and takes real action.

If these movements are properly designed, many of these drawbacks can be eliminated.

\section{iii. Personal Coaching}

This method is the oldest method of training executives in which the immediate superior of the executive gives technical advice, comments on his behavior and informs him about his progress. It is a continuous process of education on the job. The benefits of this method are that it requires minimal training costs, a trainer-trainee relationship is a daily and constructive relationship, training takes place in the work environment, and as information is immediate, knowledge is immediately implemented. Guidance is usually assumed by direct supervisors usually informally and without specific obligations. The organisation will have to set up skilled and skilled staff to guide executives who will take the lead of their trainees. This method is not the most appropriate when it is required and theoretical knowledge for the essential learning of the project.

\section{iv. Guidance - Mentoring}

This method is mainly applied to large companies, where an experienced senior member voluntarily undertakes under his protection an infinite young executive, but without the former being directly the boss of the second. This method has been attributed to the term mentoring. The company informs the candidates with whom they wish to have custody of this method, taking seriously their preferences. It then determines, on the basis of strict criteria, which senior executives will be under the tutelage of the young executives. It assigns them specific actions and monitors and controls the results of the mentor-trainee relationship. Key disadvantages of this method are that executives choose mainly to support people with the same ideas and values or individuals who, for subjective reasons, like it. The success of the method depends to a great extent on the ability and willingness of the experienced staff to act as a trainer-instructor. This method also reproduces the same culture and perpetuates the same practices of administration and finally there is the risk of exclusion of capable people by applying anti-social criteria such as ethnicity, gender, age etc.

\section{v. Participation in committees}

With this method, the training member participates as a regular member in permanent or special committees (e.g. procurement committee, tender evaluation, etc.). In this way, the executive contacts and learns the subject through his involvement in the process, gains experience in the problem-solving and decision-making process and is able to cope with various personalities and behaviors. In addition, his participation in various committees gives him the opportunity to learn about issues that concern the entire business or departments, beyond that in which he works. A disadvantage of this method is the possible time-wasting of committee members. This can be avoided by properly designing the learning process.

\section{vi. Multiple management (or board of trained executives) \\ This board usually involves middle managers from different departments to study real business-related problems. With this method they gain experience to study issues of top management interest, e.g. employee rewards, cross-sectional conflicts, promotion policy, etc. and make suggestions to the Board of Directors.}

\section{vii. Practical learning}

This method enables executives to work on real projects, analyzing and solving problems primarily in parts of the business other than their own. The trainees form groups of 4-5 groups and meet on a periodic basis to discuss their lessons and then present their suggestions to the senior executives and the head of the department where they were trained.

According to a survey by Buelens and Van der Broeck (2007) it has been found that private employees give greater value to financial gains [17]. Financial benefits are a powerful productivity incentive for employees in the private sector, particularly senior executives, as opposed to civil servants who do not associate productivity with the economic incentive. Based on this 
survey, it was found that for civil servants the internal motivations with prominent ones are related to the sense of duty and self-fulfillment. Civil servants are more preoccupied in a safe and stable work environment, with emphasis on those that exude a warm and harmonious atmosphere, in a reciprocal and respectful manner. Of particular interest is the fact that, based on the above-mentioned research, the differences in the incitement of individuals are not affected by demographics, but by their field of work. Internal incentives, and in particular non-monetary payments, are of greater value to civil servants.

In the case of Greece, despite the low level of productivity of civil servants, there is no clear policy of instigation of the government administration. Labor data surrounding the working life of civil servants frame a situation from which no substantial productivity incentives arise. It is true that no grading, salary or other motivation is linked to performance at work. Consequently, there is no real reason to increase labor intensity, with the result that the quality of the work is left to the professional diligence of the staff. The identified public sector lag in the face of the private sector in terms of motivation of human resources is attributed to the article by Bourantas et al (1999), which describes the allocation factors for performance. This study was conducted on a sample of 1,150 employees of Ministries, Public Organizations, Public Enterprises and Private Enterprises [4]. According to the above article, this lag is not only due to the non-linking of returns with financial rewards, but also to other factors such as:

- The characteristics of the content of the work, especially the variety and importance of the tasks, the autonomy of execution, the information about the results, the confusion and the conflict of roles, policies and procedures.

- The general lack of a link between efforts performance - pay.

- In the prevailing climate of public administration and, above all, in non-recognition of efforts, in heterogeneous efficiency and political intervention.

- The quality of the leadership of the immediate heads of all hierarchical levels and, above all, the functioning of rewards and the orientation of actions towards achieving the goals.

All the above can contribute to the development of public administration action by focusing on improving its overall performance. At this point it should be noted that the management of performance in the case of public organizations is a very difficult process than in the corresponding case of private enterprises. particular public institutions a) have no clear object of activity (e.g. a university aims at the education of students but also in the promotion of research, the exchange of ideas, the improvement of its financial results, etc.), b) the result of the public services is not (c) the responsibilities of a public body are combined with a number of socio-economic factors which can largely determine the end result (e.g. improving life expectancy as a result of as a result of a possible policy of the Greek Ministry of Health may not only be due to the efficiency of its actions but also to GDP growth, improved social conditions, increased educational level, efficacy of new medicines, etc.); the result produced by public bodies may consist of supplementary or substitute products (e.g. reducing smoking may involve a reduction in government revenue). As can be seen from the above, management of performance in the public sector involves considerably more parameters than in the private sector, making this process extremely difficult. However, the administration of performance in public administration is both feasible and necessary.

\section{CONCLUSIONS}

The adoption of Law 3230/2004 [14] establishes the Public Sector Management System with the aim of staffing to respond more effectively and efficiently to the modern management needs. In this context, this sets out a clear performance process, which is implemented on a yearly basis, following a top-down hierarchy, including quantitative and qualitative performance indicators and indicators. More specifically, the tLaw 3230/2004 was established the system of Management by Objectives and performance measuring in the Greek Public Administration, in terms of strategic management.

The purpose of the Law is to increase the efficiency and the effectiveness of the employees and thus of the public organizations so that the citizens will enjoy higher quality services and boosts the trust of society in transparency, exploitation of structures and in general good administration.

The Public Administration is reinforcing its policy with a further specialization with Law 4369/2016 and in particular Article 22, with the setting of a target, defined in time but also with specific measurable targets and performance indicators identified with the staff at the level of each service, so as to enhance accountability and accountability.

In particular, MBO has the meaning of weakening the 
hierarchical control, as it was in the traditional public administration and the strengthening of individualism, in the form of competition, which is implemented through the practices of the New Public Management. In this way, it is possible to measure results and compare services in terms of achieving their objectives. At the same time, citizens are informed about the performance of public services and have the possibility to complain in cases of delays and mismanagement.

The MBO and the control and inspection mechanisms of Greece have as a common component the increase of the efficiency and effectiveness of the Public Administration, but with a differential approach. The research shows that the implementation of Law $3230 / 2004$ is largely fragmented.

Moreover, it is worth pointing out that these bodies are implementing New Public Management strategies, publicizing their activities on an annual basis, showing quantitative and qualitative results of their work, highlighting transparency and accountability, characteristics that confirm the implementation of laws, which are the legislative basis for enhancing efficiency and evaluation.

This administrative reform seeks to address the pathogens of the Hellenic Public Administration to be involved in mismanagement, corruption and bureaucracy, and to connect public administration with new management and action methods by establishing an administration based on good management, more flexible and efficient. However, according to Tsekos (2018), the provisions of L.3230 / 2004, are determined in a positive direction, but the chances of their effective implementation are limited, mainly due to the culture prevailing in the political and administrative system [25].

By creating the two internal auditing bodies, Public Administration attempted to tackle bureaucracy, mismanagement and corruption within public bodies, while at the same time aiming at the efficiency, economy and efficiency of its structures. However, these bodies, as evidenced by their published annual activities, were gradually carrying out more auditing work, focusing on the legitimacy of the processes followed rather than the input, offering guidance to improve the efficiency and quality of services to the citizens. Typical features are the 2006-2009 data, where the $49 \%$ results are of a criminal and disciplinary nature, i.e. a legality control, and only the $27 \%$ are related to recommendations and suggestions for improvements to achieve profitability.
In addition, in the regulatory framework, emphasis is placed on the procedures and rules in order to implement the law on what results will be produced in terms of quality and efficiency. That is, to improve Internal Management of services there is no provision.

It is clear that the Political - Administrative Culture of Public Administration has not changed, it is based on formalism and the execution of the tasks of the public bodies, according to the letter of the law, without attempting any substantial use in the use of tools and applications of the New Public Management. Thus, the two internal bodies of the country can carry out an important task, but effective co-ordination and cooperation of all public bodies is required for the effective implementation of the political reforms.

At the same time, the unified coordination of control mechanisms through the use of common tools will intensify the audit process, thus increasing prevention and tackling more effective malpractice and irregularities. Gradually, improving developments will allow the Inspectors and Auditors of Greek Public Administration to have a more advisory and guiding role as originally foreseen. Also in this direction will be the modernization of e-Government, so as to speed up information and interconnection processes between public services, which will enhance the efficiency of the administration, reducing bureaucracy and delays.

As far as the action of the control bodies is concerned, it should be directly related to the transparency and impartiality of the results so as to change the attitude that exists so far, namely that some groups can continue to work by enriching themselves, moving through corruption mechanisms. In this context, disciplinary penalties, where identified, should be carried out at a rapid pace and directly dismissed by officials who are subject to disciplinary misconduct.

Another parameter, which should be institutionalized, is the protection of the audit bodies and their constituent members, as a number of cases produce important findings, with the result that pressures, threats and lawsuits are frequent. In this way, the auditors will be able to do their work without fear. Greek public administration needs major breakthroughs and radical structural reforms if it wants to deal effectively with corruption, mismanagement and maladministration, as lack of readiness, limited prevention mechanisms and lack of management tools, especially in earlier years, has a giant, if not consolidate- lawlessness. 
With the establishment of the inspection and control bodies, an intensive effort is being made to tackle corruption and improve public services. However, the legislative initiative is not enough. A concerted effort is required of all relevant actors to change the administrative culture in the State. This is the direction of the implementation of the New Public Management, where important tools can be utilized in order to improve the effectiveness and efficiency of the management bodies.

\section{SUGGESTIONS}

The aforementioned findings are moving within the limits of an academic approach. Specific proposals are needed to lay the foundations for a modern Public Administration and a European public administration tailored to Greek. We suggest the following:

1. Partial release of Public Enterprises and Organizations from the suffocating embarrassment of the Government. Delimit and strengthen entrepreneurial autonomy. Business planning, anthropocentric administration, pricing policy with social and developmental criteria, and absolute transparency and meritocracy in procurement policy and project assignments contribute to business autonomy.

2. Building a spirit of cooperation and trust between employees. Adoption of Schein's views on enterprise culture to combat friction among Public Enterprises executives and control of management efficiency by ensuring a mild internal environment and adapting to the effects of the external environment. The creation of winning teams requires effective action by executives under any circumstances of the internal or external environment by building a spirit of cooperation and trust while knowing and respecting the culture of the public body in order to make their actions more effective.

3. Fighting the partial ignorance and ambiguity among executives about what is happening in the Public Enterprise. It is imperative to create a reliable information system if we consider the links between a reliable information system and the effectiveness of management.

4. Create a fair remuneration system for administrators based on the current financial situation of the country. In order to eliminate differences and social inequalities, it is proposed to create a national wage system which will be adjusted to meet the strategic objectives of the enterprise and the course of the national economy.

5. Improvement of relations and confidence-building of Public Enterprises with the investment entities and creation of a support agency for foreign investors. Create "Working Groups" and "Quality Circles". It is proposed to create in each public enterprise or organization a body with technical and educational infrastructure to assist investors and the active operation of Quality Circles.

6. Develop a Business Plan. It is of the utmost importance to draw up a clear, rational and scientifically structured business plan that must define clearly and thoroughly the problems faced by the public undertaking, the objectives to be achieved, the means to achieve the general objectives, actions of strategic importance, the framework of collaboration between Government-Administration-Employees-Citizens.

7. Develop programs for the continuous education / training of managers of Public Enterprises and Organizations and attend seminars at regular intervals. Implementation of modern training methods (management games, simulation, case studies). We have mentioned above one of the most important pillars of rationalization of management and quality pursuit. This is none other than lifelong learning which is being adapted and improved in line with changes in the external environment and the organization's needs.

8. Exploitation of the international capital market. The rational management of the resources of the international capital market (especially when borrowing terms return to regularity) means raising capital from the general savings bank or from foreign investors on terms more favorable than bank lending.

Enhance competition and efficiency of public enterprises by merging complementary or homogeneous units and eliminating inactive. We need a thorough study of such an operation as well as careful handling so as not to lose any job but to instead employees in positions requiring experience, knowledge and high awareness of the task.

In conclusion, management is the most important activity of a body (public or private). It mentions the way in which resources and means are planned, organized and coordinated to achieve the objectives in a given time and to the greatest extent possible. A very promising way to achieve all these is the implementation of new public management.

\section{ACKNOWLEDGMENT}

Professor Vassilis Kefis Basil N. Kefis was born in Athens. He received his bachelor degree from the Department of Public Administration of the Panteion University of Social and Political Sciences. He continued his studies in Greece and abroad and in 1995 he obtained his $\mathrm{PhD}$ (Degree: outstanding) from the Department of Public Administration of the Panteion University. His scientific interests focus on the subjects 
of Economic Policy, Total Quality Management, Strategic Management, Human Resource Management, Business Plan, and eGovernment. Today he works as a Professor of the same Department. He has participated in scientific conferences, both in Greece and abroad. He is a Dean of the School of Economics and Public Administration of the Panteion University and a member of organizations, chambers and institutions that promote the economic and administrative sciences.

Dr. Panagiota Xanthopoulou was born in Athens and currently works as a Tutor at Private Educational Institutions as well as in Schools and Universities of Tertiary Education as an Adjunct Lecturer. She graduated from the Public Administration Department (Direction of Public Finance) of the Panteion University. Since 2016 she holds a PhD degree from the department of Public Administration at Panteion University with main subject the contribution of elearning in Social Sciences. She has participated in many conferences with the topics of youth entrepreneurship, education, corporate governance and human resources. She has many publications and articles in Greek and international journals. Her research and writing interests include the areas of Public Administration, Total Quality Management and Education, with an emphasis on adult and e-learning education.

\section{REFERENCES}

1. Etzioni, P. Marcus, R.K. Merton, A. Reiss, J.Q.Wilson, \& H. White, Organizations. Prentice-Hall Publishing Co., Englewood Cliffs, NJ.,1964.

2. Bimpitsos, \& E. Petridou, "A transdisciplinary approach to training: preliminary research findings based on a case analysis", European Journal of Training and Development, vol.36, no.9, pp. 911-929, 2012.

3. Spanou, "European Integration in Administrative Terms: A Framework for Analysis and the Greek Case”, Journal of European Public Policy, Vol. 5, pp. 467-84, September 1998.

4. Bourantas \& N. Papalexandris, "Personality traits discriminating between employees in public-and in privatesector organizations", International Journal of Human Resource Management, vol. 10, no.5, pp. 858-869, February 2011.
5. McAlesse, Economics for business studies-competition, long term stability and globalization, Typothito Ed. Athens, 2005

6. D.A Sotiropoulos, \& L. Christopoulos, Overregulation and Ineffective Legislation in Greece, Dianeosis Ed., Athens, 2016. [in Greek]

7. D. Osborne, \& T. Gaebler, "Reinventing Government", Journal of Leisure Research, vol.27, no.3, pp.302-304, December 2017 European Union, 2015, p. 82

8. W. Scharpf, \& V. A. Schmidt, Welfare and Work in the Open Economy: Volume I: From Vulnerability to Competitivesness in Comparative Perspective (Vol. 1). OUP Oxford, 2000.

9. G. Bouckaert, \& C. Pollitt, Public Management Reform. A Comparative Analysis-New Public Management, Governance and the Neo-Weberian State, Oxford University Press, Oxford, 2011.

10. Fang, "Lottery versus all-pay auction models of lobbying", Public Choice, vol. 112, no.3-4, pp.351-371, September 2002

11. J. E. Lane, The public sector: concepts, models and approaches. Sage, 2001, pp.146-159.

12. J. Wallis, \& B. Dollery, "Leadership and economic theories of nonprofit organizations", Review of Policy Research, vol.22, no.4, pp.483-499, July 2005.

13. Law 3230/2004

14. M. Bovens, "Public accountability: A framework for the analysis and assessment of accountability arrangements in the public domain" Unpublished paper.

15. M. Buelens, \& H. Van den Broeck, "An analysis of differences in work motivation between public and private sector organizations", Public administration review, vol. 67, no.1, pp.65-74, February 2007.

16. M. Dela Rama, "Corporate governance and corruption: Ethical dilemmas of Asian business groups", Journal of Business Ethics, vol.109, no.4, pp. 501-519, September 2012.

17. M. Hammer \& J. Champy, Reengineering the Corporation: Manifesto for Business Revolution, A. Zondervan, 2009.

18. M. Minogue, C. Polidano, \& D. Hulme, Beyond the new public management, Edward Elgar Publishing, 1998, pp. 1-14.

19. P.A Hall, \& D. Soskice, Varieties of capitalism: The institutional foundations of comparative advantage, OUP Oxford, 2001.

20. Palgrave Macmillan, Cham, 2018. Substantial Failures". In Evaluating Reforms of Local Public and Social Services in Europe (pp. 315-331). Palgrave Macmillan, Cham, 2018.

21. R. N. McKean, Efficiency in government through systems analysis with emphasis on water resource development, John Wiley \& Sons Inc, 1958

22. T. Curristine, Z. Lonti, \& I. Joumard, "Improving public sector efficiency: challenges and opportunities", OECD Journal on Budgeting, vol.7, no.1, p.161, July 2007.

23. T. N. Tsekos, \& A. Triantafyllopoulou, "A, Policy Evaluation Capacity in Greek Local Government: Formal Implementation and Substantial Failures". In Evaluating Reforms of Local Public and Social Services in Europe (pp. 315-331).

24. kefis, integrated management: basic principles for modern business units, kritiki ed.,athens, 2005 [in greek] 